\title{
Lifetime Prediction of Lead-Acid Batteries in Base-Transceiver Station
}

\author{
Unggul Wibawa ${ }^{\# 1}$, Bobby Pratama ${ }^{\# 2}$, Rini Nur Hasanah ${ }^{\# 3}$ \\ ${ }^{\#}$ Electrical Engineering Department, Faculty of Engineering, Brawijaya University, \\ Jl. MT Haryono 167 Malang 65145 Indonesia \\ E-mail: ${ }^{1}$ unggul@ub.ac.id; ${ }^{2}$ bxpratama@yahoo.com; ${ }^{3}$ rini.hasanah@ub.ac.id
}

\begin{abstract}
The battery is an essential component in providing continuous electricity supply using renewable energy sources. It can be found in many daily applications, such as in the telecommunication system, radio microwave system, emergency lighting, the backup system of power plants, even in a photovoltaic system. It is often used as the backup source in case of a failure in the main supply system. The duration of how long the battery can still supply energy to loads without being charged is defined as the battery autonomy day. If during its daily utilization the battery often exceeds its autonomy day, it can result in the deterioration of the battery lifetime. It produces the deviation of the battery lifetime specification which has been previously determined by the manufacturer. This paper presents the results of battery lifetime prediction at a base-transceiver station (BTS) of Telkomsel Company in Indonesia. It has two main purposes which are to evaluate the policy of autonomy day and to predict the remaining lifetime of the battery before reaching its time limit. The obtained results show that there have been some alterations from the batteries' former policy of autonomy day, from 72 hours to 43.03 hours and 43.26 hours for both existing batteries respectively with considered depth-of-discharge (DOD) of $20 \%$. By using a linear data curve fitting, the results of calculation and analysis indicate that the remaining useful lifetime of both batteries were 5.72 years and 5.77 years. Another approach using an exponential data curve fitting resulted in the remaining lifetime of 7.12 years and 7.16 years for both batteries respectively.
\end{abstract}

Keywords - autonomy day; battery lifetime; lead-acid battery.

\section{INTRODUCTION}

Electricity is one of the daily necessities which rises exponentially from year to year as a result of the expanding technology and the complex human needs. The sources of electricity are nowadays still dominated by the fossil energy, which is widely known to become the main cause of environmental pollution and global warming. The energy demand has been continuously increasing from time to time, but the energy supply has been decreasing in the last three decades [1]. As many types of research have proven, this problem demands a very serious concern because during the recent hundred years the average global temperature has been rising within the range of $0.74 \pm 0.18^{\circ} \mathrm{C}$ [2]. One of the wise solutions to this problem is the use of renewable energy sources.

Indonesia is a tropical country which is endowed with various choices of alternative energy resources. There is a great potential to harness energy from the sun radiation. This is a good opportunity for many enterprises and companies to turn into the use of more eco-friendly energy supply system, as the Indonesian government has also the commitment and even provides some interesting incentives to support such type of initiatives.

Telkomsel is the most important telecommunication company in Indonesia. It possesses many base-transceiver stations (BTS) in various locations to support their operation services around the country. In a telecommunication system, a BTS is an equipment to facilitate the wireless communication between the user equipment and the telecommunication network. In general, the BTS is supplied using the power provided by the state electricity company, using a diesel-generator set, and/or using a photovoltaic (PV) system. The main limit of the PV systems is the low conversion efficiency of the PV panels, which is strongly influenced by their operating temperatures [3]. A combination of supply systems is normally adopted to provide a power back-up during a failure of the main supply system. In the case of a PV system, the battery utilization must consider the duration of how long it can still support the loads without being charged, which is defined as its 'autonomy day'. The autonomy day has also a close connection to the lifetime of a battery. These two variables must be controlled simultaneously, as a part of the energy management system [4]. 


\section{MATERIAL AND METHOD}

\section{A. Battery Lifetime Prediction}

The battery lifetime is defined as an estimated time for a battery to support the loads until the energy inside it is used up. The designed lifetime is normally specified and determined during the manufacturing process based on the assumption of standby operation at $25^{\circ} \mathrm{C}$ [5]. Some factors which affect the battery lifetime are [6]:

- State-of-Charge (SOC) and Depth-of-Discharge (DOD)

- Corrosion

- Active material degradation

- Temperature

- Overcharging

The SOC represents a ratio of the remaining useful capacity to its full capacity, being stated in percentage. For a lead-acid battery, the SOC is proportional to its open circuit voltage [7], as shown in Fig. 1.

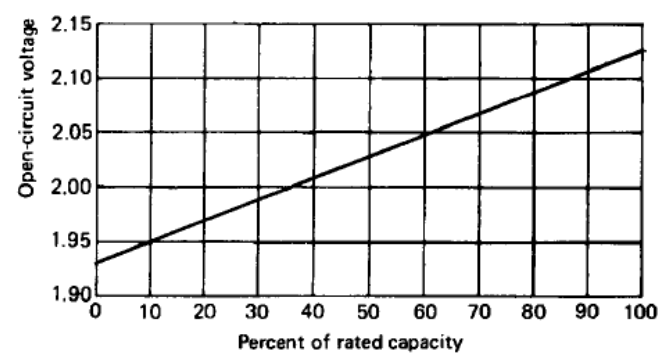

Fig. 1 The open circuit voltage as a function of the state-of-charge

To determine the SOC, a model presented in [8] can be used, as expressed in Eq. (1).

$$
\operatorname{SOC}(t)=\operatorname{SOC}(0)+\frac{1}{C_{N}} \int i_{B}(\tau) d \tau
$$

where $\operatorname{SOC}(0)$ is the initial state of charge of the battery (in \%), $\mathrm{C}_{\mathrm{N}}$ is the nominal capacity of the battery $(\mathrm{Ah}), \mathrm{i}_{\mathrm{B}}(\tau)$ is the battery current (A) at time $\tau$, and $\tau$ is the operation time (in hours).

A battery is at its best usage when operating at its $80 \%$ capacity, which means that it has only delivered $20 \%$ of its energy or being called as its depth of discharge (DOD) [9][13]. The relationship between the charging voltage and the cycle life of a battery for various DOD is shown in Fig 2. As seen, there is a certain charging voltage value which will give the maximum cycle life at a certain DOD level.

A low-percentage condition of SOC which occurs repeatedly during a very long time can result in a mechanical stress on the active material of the battery. It damages the plate surface of the sulfate crystal so that it cannot take part anymore in the chemical reaction [6]. The global aging at the cathode triggers the deterioration of the battery capacity each time it is used, as expressed in Eq. (2).

$$
\mathrm{C}_{\text {deg }}(\mathrm{t})=\mathrm{C}_{\text {deg limit }} \mathrm{e}^{-\mathrm{C}_{\mathrm{Z}}\left(1-\frac{\mathrm{Z}_{\mathrm{W}}(\mathrm{t})}{1.6 \mathrm{Z}_{\mathrm{IEC}}}\right)}
$$

with

$$
\begin{gathered}
\mathrm{Z}_{\mathrm{W}}(\mathrm{t})=\frac{1}{\mathrm{C}_{\mathrm{N}}} \sum_{\tau=0}^{\mathrm{t}} \mathrm{I}_{\mathrm{Z}}(\tau) \Delta \mathrm{t} \\
\mathrm{I}_{\mathrm{Z}}=\left\{\begin{array}{cc}
\left|\mathrm{I}_{\mathrm{B}}\right| & \mathrm{I}_{\mathrm{B}}<0 \\
0 & \mathrm{I}_{\mathrm{B}}>0
\end{array}\right.
\end{gathered}
$$

where $C_{\text {deg }}$ represents the capacity loss because of the material degradation (in $\mathrm{Ah}$ ), $\mathrm{C}_{\mathrm{deg} \text { limit }}$ is the capacity limit (i.e. 0.8 of nominal capacity $\mathrm{C}_{\mathrm{N}}$ ), $\mathrm{C}_{\mathrm{Z}}$ is a constant, $\mathrm{Z}_{\mathrm{IEC}}$ is the cycles number as determined by IEC, and $I_{Z}$ is the battery current (in A).

The remaining capacity of the battery can be found [6],

$$
\mathrm{C}_{\mathrm{R}}(\mathrm{t})=\mathrm{C}_{0}-\mathrm{C}_{\text {corr }}(\mathrm{t})-\mathrm{C}_{\text {deg }}(\mathrm{t})
$$

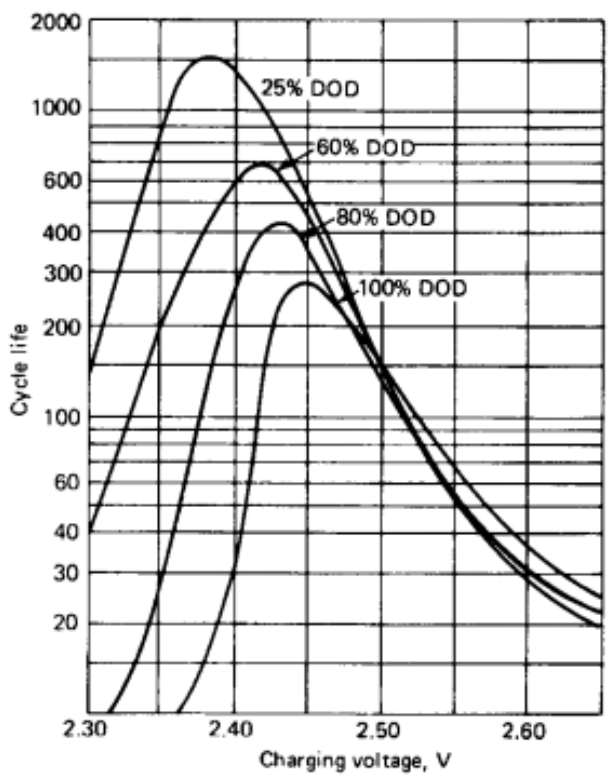

Fig. 2 The relationship between the charging voltage and the cycle life of a battery for various DOD values [8]

Corrosion is an unavoidable process occurring on everything which can oxidize [9]-[10]. The loss of capacity caused by the corrosion $\mathrm{C}_{\text {corr }}$ can be obtained using Eq. (6),

$$
\begin{gathered}
\mathrm{C}_{\text {corr }}(\mathrm{t})=\mathrm{C}_{\text {corr limit }} \frac{\Delta \mathrm{W}(\mathrm{t})}{\Delta \mathrm{W}_{\text {limit }}} \\
\mathrm{C}_{\text {corr limit }}=0.16 \mathrm{C}_{\mathrm{d}}
\end{gathered}
$$

with

where the notation $C_{d}$ represents the normalized capacity value of the battery discharge (i.e. 1.642). Based on the value of open-circuit voltage $U$, the loss of cathode plate dimension $\Delta \mathrm{W}$ is found using Eqs. (8)-(9), and $\Delta \mathrm{W}_{\text {limit }}$ is determined using Eq. (10).

For $\mathrm{U}<1.74 \mathrm{~V}$,

$$
\Delta \mathrm{W}(\mathrm{t})=\mathrm{k}_{\mathrm{s}}\left(\frac{\Delta \mathrm{W}(\mathrm{t}-1)}{\mathrm{k}_{\mathrm{s}}}\right)^{1 / 0.6}+\Delta \mathrm{t}
$$

For $\mathrm{U} \geq 1.74 \mathrm{~V}$,

$$
\begin{aligned}
\Delta \mathrm{W}(\mathrm{t}) & =\Delta \mathrm{W}(\mathrm{t}-1)+\mathrm{k}_{\mathrm{s}} \Delta \mathrm{t} \\
\Delta \mathrm{W}_{\text {limit }} & =365 \bullet 24 \bullet \mathrm{k}_{\mathrm{s}} \mathrm{L}_{80 \%}
\end{aligned}
$$

where $\mathrm{k}_{\mathrm{s}}$ is corrosion rate $(0.0435 \mathrm{mpy})$ and $\mathrm{L}_{80 \%}$ is the lifetime of battery in years as given in the datasheet.

The open-circuit voltage $U$ is determined based on the value of battery current $I_{B}$ using Eqs. (10)-(11), with some notations is given in Table 1 .

For $\mathrm{I}_{\mathrm{B}}>0$,

$$
\mathrm{U}=\mathrm{U}(0)-\mathrm{gH}+\rho_{\mathrm{c}} \frac{\mathrm{I}_{\mathrm{B}}}{\mathrm{C}_{\mathrm{N}}}+0.5 \frac{\rho_{\mathrm{c}} \mathrm{M}_{\mathrm{c}} \mathrm{I}_{\mathrm{B}} \mathrm{F}}{\mathrm{C}_{\mathrm{N}}\left(\mathrm{C}_{\mathrm{c}}-\mathrm{F}\right)}
$$

For $\mathrm{I}_{\mathrm{B}} \leq 0$,

$$
\mathrm{U}=\mathrm{U}(0)-\mathrm{gH}+\rho_{\mathrm{d}} \frac{\mathrm{I}_{\mathrm{B}}}{\mathrm{C}_{\mathrm{N}}}+0.5 \frac{\rho_{\mathrm{d}} \mathrm{M}_{\mathrm{d}} \mathrm{I}_{\mathrm{B}} \mathrm{F}}{\mathrm{C}_{\mathrm{N}}\left(\mathrm{C}_{\mathrm{d}}-\mathrm{H}\right)}
$$


TABLE I

LEAD-ACID BATTERY PARAMETERS AND VARIABLES [9]

\begin{tabular}{|l|l|c|}
\hline \multicolumn{1}{|c|}{ Parameter } & \multicolumn{1}{c|}{ Description } & Value \\
\hline $\mathrm{U}(0)$ & Open-circuit voltage & 2 volt \\
\hline $\mathrm{g}$ & $\begin{array}{l}\text { Coefficient relating the U } \\
\text { variation with respect to } \\
\text { SOC }\end{array}$ & 0.054 volt \\
\hline $\mathrm{H}$ & Normal DOD value & {$[\%]$} \\
\hline $\mathrm{F}$ & Normal SOC value & {$[\%]$} \\
\hline$\rho_{\mathrm{c}}, \rho_{\mathrm{d}}$ & $\begin{array}{l}\text { Internal resistance at } \\
\text { charging, discharging }\end{array}$ & $\begin{array}{l}0.43609, \\
0.37885\end{array}$ \\
\hline $\mathrm{I}_{\mathrm{B}}$ & Battery current & {$[\mathrm{A}]$} \\
\hline \multirow{2}{*}{$\mathrm{M}_{\mathrm{c}}, \mathrm{M}_{\mathrm{d}}$} & Coefficient of $\rho$ variation & 0.36488, \\
& with respect to SOC & 0.28957 \\
\hline \multirow{2}{*}{$\mathrm{C}_{\mathrm{c}}, \mathrm{C}_{\mathrm{d}}$} & Normalized capacity at & $1.001,1.642$ \\
\hline
\end{tabular}

The operating temperature influences the battery capacity and voltage. At a higher temperature, the internal resistance of the battery is small, hence the voltage is higher and the capacity being transferred is also higher [7]. The relationship between the operating temperature and the number of cycles of a battery is represented in Fig. 3, based on Eq. (13)-Eq. (14).

For $0<\mathrm{T} \leq 20^{\circ} \mathrm{C}$, the number of cycles $\mathrm{N}_{\mathrm{C}}$ is obtained as

$$
\mathrm{N}_{\mathrm{C}(\mathrm{T})}(\%)=100 \%
$$

For $\mathrm{T}>20^{\circ} \mathrm{C}$, the number of cycles $\mathrm{N}_{\mathrm{C}}$ is obtained as

$$
\mathrm{N}_{\mathrm{C}(\mathrm{T})}(\%)=\left(37.68 \mathrm{~T}^{-1.101}-0.3897\right) \times 100 \%
$$

The overcharging occurs when the battery charging exceeds its capacity ([11]-[12]). This condition may accelerate the corrosion rate on the cathode, producing $\mathrm{O}_{2}$ and $\mathrm{H}_{2}$. If the gasification is excessive, water vaporization may happen, which makes the battery over-oxidated and may cause an explosion [7].

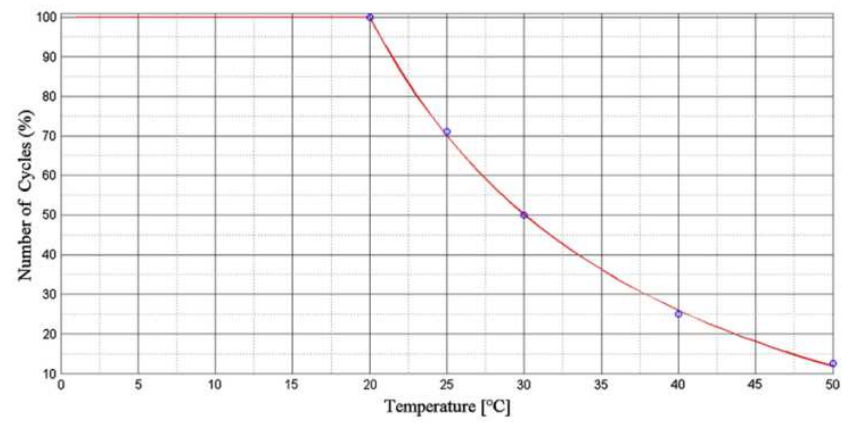

Fig. 3 The relationship between the operating temperature and the number of cycles of a battery [10]

\section{RESULTS AND DISCUSSION}

The battery lifetime prediction method proposed in this paper has been implemented by switching the batteries to a stand-alone mode. The data were then obtained by measuring the voltage and current of the batteries during its initial autonomy day, which was 72 hours. The specification of the batteries under consideration is given in Table 2 .

\section{A. Battery Voltage Measurement Results}

The measurement results of battery voltage on the standalone mode are given in Fig 4. The measured voltages are the end-voltage or cut-off voltage of the battery, which is the recommended voltage to start the discharging process [11] [13].

TABLE II

SPECIFICATION OF THE BATTERY A600 16 OPZV 2300

\begin{tabular}{|l|l|}
\hline \multicolumn{1}{|c|}{ Parameter } & \multicolumn{1}{c|}{ Value } \\
\hline Nominal voltage & $2 \mathrm{~V}$ \\
\hline Nominal capacity & $2300 \mathrm{Ah}$ \\
\hline Temperature & $250 \mathrm{C}$ \\
\hline Max charge current & $200 \mathrm{~A}$ \\
\hline Cells per bank & 24 \\
\hline Bank & 2 \\
\hline Lifetime expectancy & 18 years at 20OC to $80 \%$ SOC \\
\hline
\end{tabular}

As seen, the evolution of the discharging process for both batteries is similar. Because of the on-site condition of the measurement, the voltage and current measurements were not performed when the battery voltage is at its maximum value. The data at the initial measurement time $(t=0)$ has been taken as the reference data to calculate the initial value of the battery state of charge.

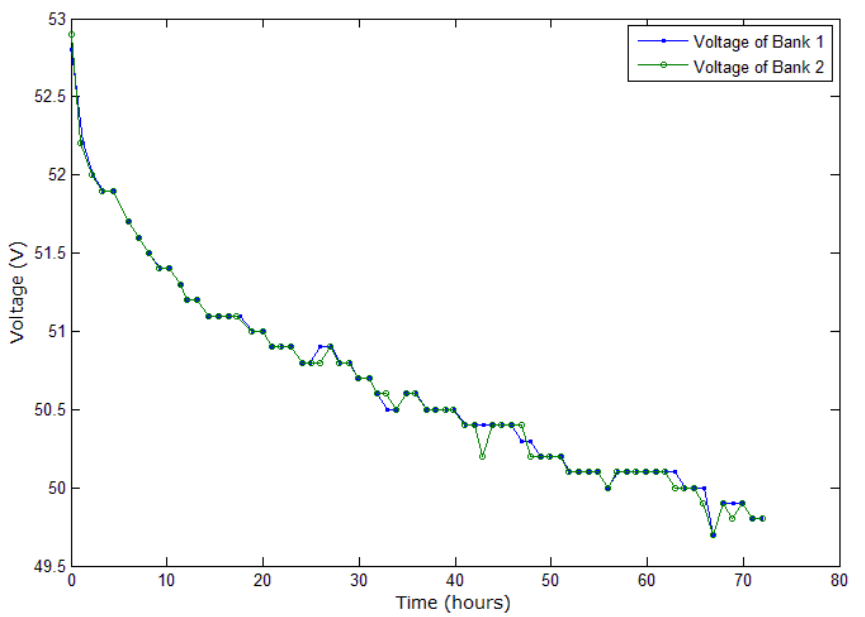

Fig. 4 The experiment results on the battery voltage vs. time

At the beginning of the measurement, the terminal voltage of battery bank 1 was $52.8 \mathrm{~V}$ whereas that of the second one was $52.9 \mathrm{~V}$. At the time the batteries reached the end of their autonomy day, the battery voltage drops from $52.8 \mathrm{~V}$ to 49.8 $\mathrm{V}$ in the first bank and from $52.9 \mathrm{~V}$ to $49.8 \mathrm{~V}$ in the second bank.

\section{B. Battery Current Measurement Results}

The measurement results of battery current on the standalone mode are given in Fig 5. The measured currents refer to the load currents because the batteries were applied in series with the loads. It was the current produced by the battery to supply the load at the base-transceiver station during the specified autonomy day.

As can be observed in Fig. 5, at the initial time the first bank was injected with a current of $4.05 \mathrm{~A}$ and the second one with $4.02 \mathrm{~A}$, putting both batteries in charging conditions. The flowing current into batteries would become more and more smaller as the number of charges in the battery become more and more higher. At a certain moment the battery could not accommodate anymore the incoming current, and it reached the fully-charged state. 


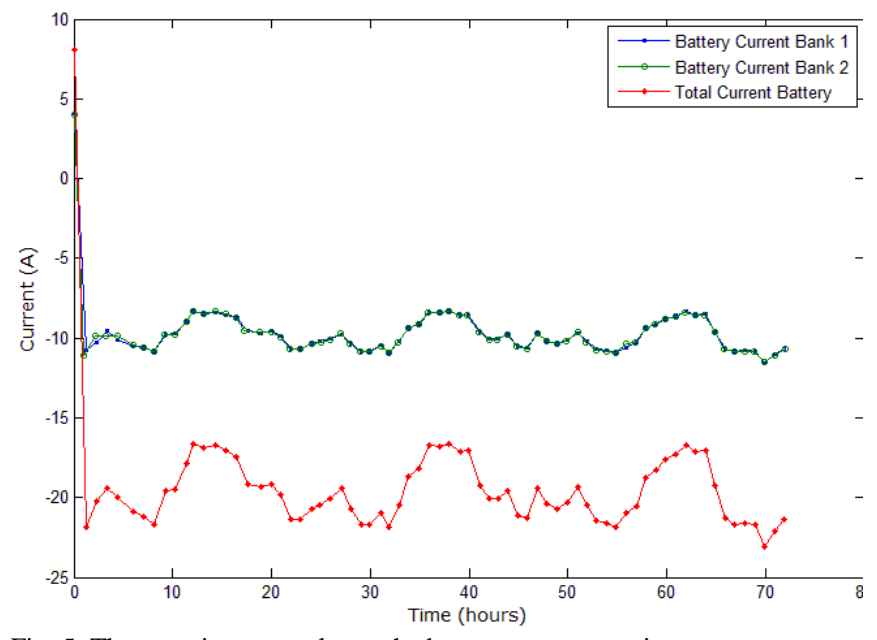

Fig. 5 The experiment results on the battery current vs. time

Because of the on-site condition, the initial measurements were not performed when the current value was 0A. The battery current measured using a clamp meter at full-load condition was of negative value as it flew in the opposite direction toward the load. The load current varies along the time because the data traffic at the system were not the same all the time.

\section{Battery State-of-Charge}

The battery capacity, which has a different value depending on the load current at each time, has been measured in discharging mode. The measurement has been done based on the open-circuit voltage of the battery at the initial state of measurement $(t=0)$. The remaining SOC at each time has been measured using the elaboration of the Eq. (1). The integration of the current value over the time will represent a trapezoidal area. Since the current being delivered at each time is different, the integration could be replaced with a summing operation as follows.

$$
\begin{gathered}
\operatorname{SOC}(\mathrm{t})=\operatorname{SOC}(0)+\frac{1}{\mathrm{C}_{\mathrm{N}}}\left(\sum_{\mathrm{t}=1}^{\mathrm{t}} \mathrm{L}_{\mathrm{t}}\right) \times 100 \% \\
\operatorname{SOC}(\mathrm{t})=\operatorname{SOC}(0)+ \\
\frac{1}{\mathrm{C}_{\mathrm{N}}}\left(\sum_{\mathrm{t}=1}^{\mathrm{t}} \frac{1}{2} \mathrm{x}\left[\mathrm{i}_{\mathrm{B}}(\mathrm{t})+\mathrm{i}_{\mathrm{B}}(\mathrm{t}-1)\right] \mathrm{x}\right)[\tau(\mathrm{t})+\tau(\mathrm{t}-1)] \times 100 \%
\end{gathered}
$$

When $t$ reaches 1 , the equation becomes

$$
\operatorname{SOC}(1)=\operatorname{SOC}(0)+\frac{1}{2 C_{N}} \times\left[i_{B}(1)+i_{B}(0)\right] \times[\tau(1)-\tau(0)] \times 100 \%
$$

When $\mathrm{t}$ reaches $\mathrm{t}+1$ for the next period, the equation becomes

$$
\begin{aligned}
& \operatorname{SOC}(\mathrm{t}+1)=\operatorname{SOC}(0)+ \\
& \frac{1}{2 \mathrm{C}_{\mathrm{N}}} \times\left\{\begin{array}{l}
{\left[\mathrm{i}_{\mathrm{B}}(\mathrm{t})+\mathrm{i}_{\mathrm{B}}(0)\right] \times[\tau(\mathrm{t})-\tau(0)]+} \\
{\left[\mathrm{i}_{\mathrm{B}}(\mathrm{t}+1)+\mathrm{i}_{\mathrm{B}}(t)\right] \times[\tau(\mathrm{t}+1)-\tau(t)]}
\end{array}\right\} \times 100 \%
\end{aligned}
$$

which can be simplified furthermore as

$$
\begin{aligned}
& \operatorname{SOC}(\mathrm{t}+1)=\operatorname{SOC}(\mathrm{t})+ \\
& \frac{1}{2 \mathrm{C}_{\mathrm{N}}} \times\left[\mathrm{i}_{\mathrm{B}}(\mathrm{t}+1)+\mathrm{i}_{\mathrm{B}}(\mathrm{t})\right] \times\left[\tau\left(\mathrm{t} \_1\right)-\tau(\mathrm{t})\right] \times 100 \%
\end{aligned}
$$

Using Eq. (19) the SOC of the batteries can be presented as shown in Fig 6.

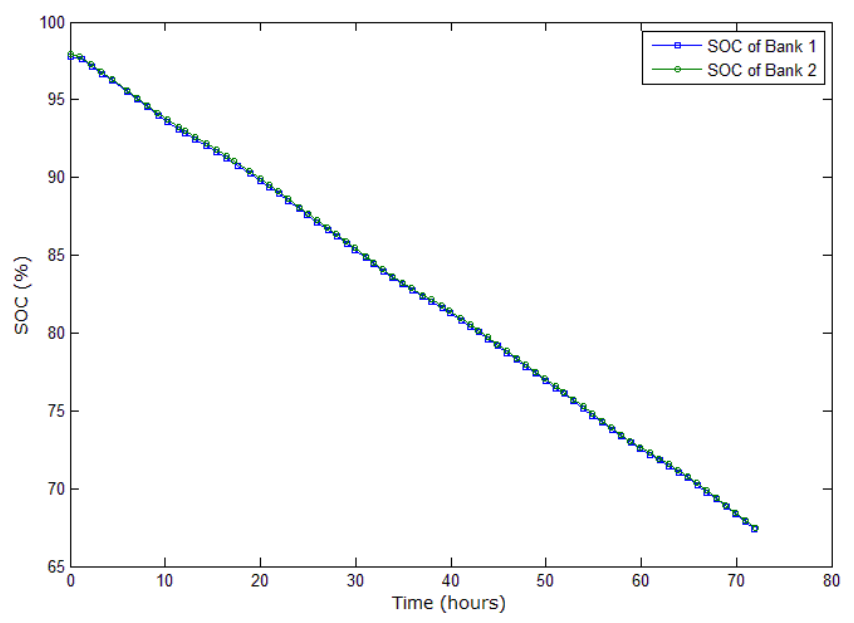

Fig. 6 The battery SOC vs. time

As shown, the initial state-of-charge of the first bank was $97.78 \%$ and $97.96 \%$ for the second bank. It can be understood that the SOC of both battery banks was almost linear with respect to time because the battery current was almost constant all the time. As it reached the autonomy day, the first bank was at its $67.37 \%$ of SOC and $67.44 \%$ SOC for the second bank.

Based on the curve in Fig. 6, the time needed for each bank to reach its $80 \%$ SOC was 43.03 hours for the first bank and 43.26 hours for the second bank. If the autonomy day were set to be 72 hours, the battery capacity would need to be upgraded. By modifying Eq. (15), the required capacity for the first bank must have been at least $3934 \mathrm{Ah}$ and 3907 Ah for the second bank. As the banks were installed in parallel, the capacity must have been the same. The manufacturer data showed that the available capacity around 3900Ah could be fulfilled using the battery nominal capacity of 3950Ah if it were required to have 3 days of autonomy with the remaining capacity of $80 \%$ at each battery.

\section{Battery Lifetime Prediction Results}

A battery cycle is composed of the discharge time and recharge time. In general, the battery manufacturers provide the data of the available capacity as a function of charging time for the various percentage of DOD, as shown in Fig. 7.

As seen, it indicates the characteristics of battery recharging at $2.25 \mathrm{Vpc}$, by assuming that after using up the battery until its $80 \%$ capacity, it would be recharged during approximately 20 hours until reaching its maximum capacity again.

During the measurement, the obtained battery cycle of the first battery bank was 63.03 hours, whereas the cycle of the second battery bank was 63.26 hours. The manufacturer's data showed that for the A600 battery type considered in this paper, the lifetime was estimated to be as long as 18 years under the operating temperature of $20^{\circ} \mathrm{C}$ at $80 \%$ of its capacity.

If the temperature rises, the life expectancy of the battery will drop and can be calculated using Eq. (14) by considering the operating temperature of $25^{\circ} \mathrm{C}$. It was obtained that the life expectancy dropped to 12.58 years. In 
order to convert the life expectancy into the number of cycles, Eq. (20) can be used.

$$
\mathrm{n}_{\text {cycle }}=\frac{\text { life expectancy }(\text { years })}{\text { cycle(hours })} \times 365 \times 24
$$

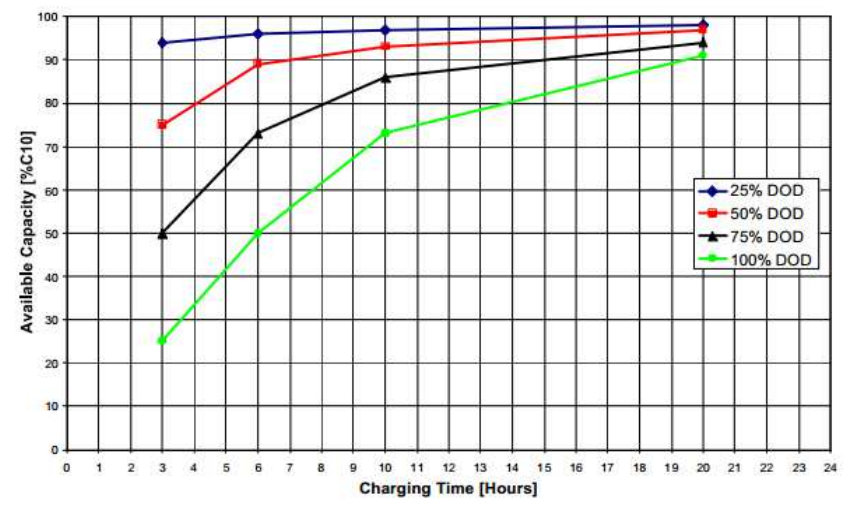

Fig. 7 The typical battery recharging data provided by manufacturers [14]

By using Eq. (20) it was found out that the first battery bank had 1748 cycles, whereas the second battery bank had 1742 cycles. By assuming that these cycles were repeated daily, the batteries' lifetime could be predicted using the formula of the remaining capacity of the proposed models, as shown in Eq. (2)-(12), based on the parameters of leadacid batteries given in Table 1 . The obtained results are shown in Fig 8.

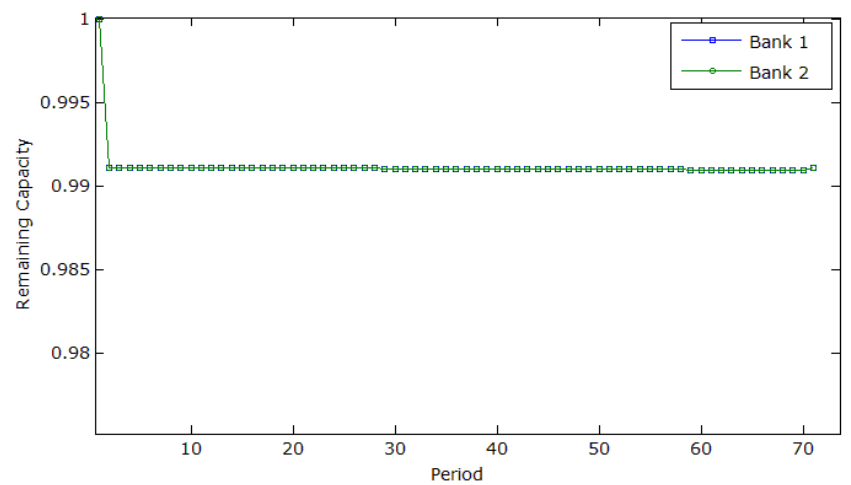

Fig. 8 The remaining battery capacity

In order to get the relationship between the remaining battery capacity and the period number, an approach using the linear and exponential curve fitting has been considered. The linear curve fitting result for the data obtained in the first battery bank is given in Fig. 9, whereas the result of the second battery bank is given in Fig. 10, respectively.

As seen in Fig. 9 and Fig. 10, the abscise represents the period and the ordinate represents the battery capacity. The period is the discharge time for the battery to reach its $80 \%$ capacity. By substituting the ordinate value with 0.8 in the curve of the first bank, the required period to be reached is 75088 or the same as 1746 cycles, being equal approximately to 12.56 years. For the second bank, the required period number is approximately 75089 , being equal to 1746 cycles or 12.6 years.

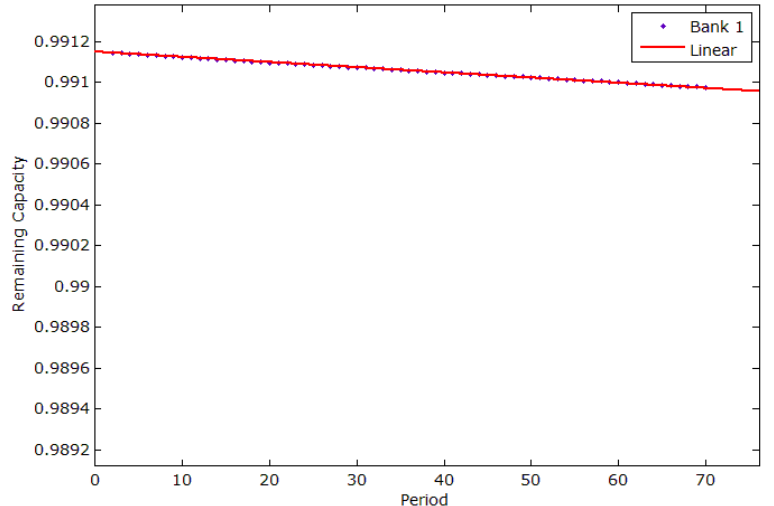

Fig. 9 The linear curve fitting results of the remaining capacity data as a function of the cycle-number for the first battery bank

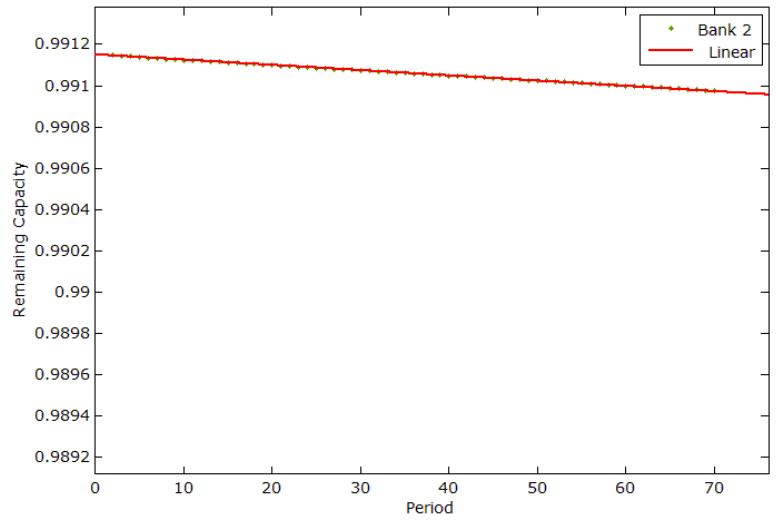

10 The linear curve fitting results of the remaining capacity function of the cycle-number for the second battery bank

The approach using exponential curve fitting is shown in Fig. 11 for the first battery bank, whereas for the second battery bank is given in Fig. 12. By substituting the ordinate value with 0.8 , it has been found that the first battery bank had to pass 83413 periods, being equal to 1940 cycles or 13.95 years.

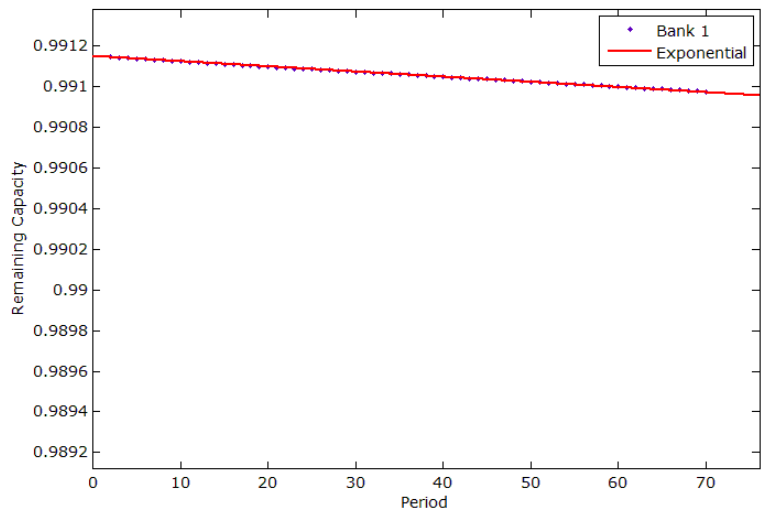

Fig. 11 The exponential curve fitting results of the remaining capacity data as a function of the cycle-number for the first battery bank 


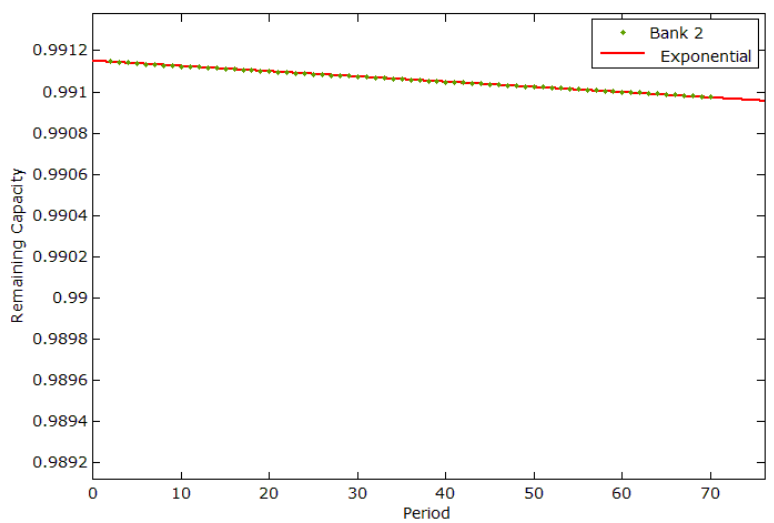

Fig. 12 The exponential curve fitting results of the remaining capacity data as a function of the cycle-number for the second battery bank

\section{CONCLUSIONS}

An adopted model and method to predict the lifetime of a battery as the energy source of a BTS in a telecommunication system has been presented. The prediction has been based on the measurement and observation of the existing policy in operating the battery according to the required BTS loading variation and condition. Various factors influencing the battery lifetime, including the SOC, DOD, corrosion, active material degradation, temperature and overcharging condition, have been considered, bringing to the prediction of the remaining lifetime expectancy which is shorter than the initial autonomy day determined by the battery manufacturer.

The research results also implied that it would be interesting to design an adaptive battery controller to keep steady the battery cycles as it repeats through times. The controller can help in maintaining the best possible performance of the batteries for various loading conditions, in supporting the best continuity of the service, and in monitoring the batteries' health in order to get the best period for replacement intervals in the future. Moreover, by optimizing the conditions of charging and discharging, the probability of a sudden failure being caused by the excessive charging or discharging could be minimized.

It is possible to have different battery models for different cases to take into account unpredicted variables that which may have a great role in deteriorating the life expectancy of the batteries. By using different models better comparison can be performed to get the best battery lifetime prediction.

\section{ACKNOWLEDGMENT}

The authors would like to express their gratitude to the Task Force of the World Class University Program and the International Scientific Publication Office of Brawijaya
University for enabling the dissemination of this research paper.

\section{REFERENCES}

[1] T.K. Hariadi, P.J. Prahara, S.B. Lesmana, and R. Saidi, "Energy efficiency and policy analysis for household in DI Yogyakarta (Yogyakarta Special Region) Indonesia," International Journal on Advance Science Engineering Information Technology (IJASEIT), vol. 6 , no. 3, pp. 329-333, 2016.

[2] Intergovernmental Panel on Climate Change Working Group,"Climate Change 2007: Synthesis Report," Valencia, 2007.

[3] A.R. Amelia, Y.M. Irwan, W.Z. Leow, M Irwanto, I. Safwati, and M. Zhafarina, "Investigation of the effect temperature on photovoltaic (PV) panel output performance," International Journal on Advance Science Engineering Information Technology (IJASEIT), vol. 6, no. 5, pp. 682-688, 2016.

[4] T.A.T.Mohd, M.K. Hassan, I. Aris, C.S. Azura, and B.S.K.K Ibrahim, "Application of Fuzzy Logic in multi-mode driving for a battery electric vehicle energy management," International Journal on Advance Science Engineering Information Technology (IJASEIT), vol. 7, no. 1, pp. $284-290,2017$.

[5] S. Drouilhert and B. Johnson, "A battery life prediction method for hybrid power applications," National Renewable Energy Laboratory, 1997.

[6] R. Dufo-López, J.M. Lujano-Rojas, and J.L. BernalAgustin,"Comparison of different lead-acid battery lifetime prediction models for use in simulation of stand-alone photovoltaic systems," Applied Energy, pp. 242-253, 2014.

[7] D. Linden and T.B. Reddy, Handbook of Batteries, 3rd ed. New York: McGraw-Hill, Inc., 2001.

[8] R. Langella, A. Testa, and C. Ventre, "A new model of lead-acid batteries lifetime in smart grid scenario," in Proceedings of 2014 IEEE International Energy Conference (ENERGYCON), Dubrovnik, Croatia, 13-16 May 2014, pp. 1343 - 1348.

[9] D. Montenegro, S. Rodríguez, J.R. Fuelagán, and J.B. Jiménez, “An estimation method of state of charge and lifetime for lead-acid batteries in smart grid scenario," in Proceedings of 2015 IEEE PES Innovative Smart Grid Technologies Latin America (ISGT LATAM), Montevideo, Uruguay, 5-7 October 2015, pp. 564 - 569.

[10] T.M. Layadi, G. Champeonis, M. Mostefai, and D. Abbes, Lifetime Estimation Tool of Lead-Acid Batteries for Hybird Power Sources Design. Simulation Modelling Practice and Theory, pp. 36-48, 2015.

[11] B. Vulturescu, S. Butterbach, and C. Forgez, "Experimental considerations on the battery lifetime of a hybrid power source made of ultracapacitors and lead-acid batteries," IEEE Journal of Emerging and Selected Topics in Power Electronics, vol. 2, Issue 3, pp. 701709, 2014.

[12] V. Agarwal, K. Uthaichana, R.A. DeCarlo, and L.H. Tsoukalas, "Development and validation of a battery model useful for discharging and charging power control and lifetime estimation," IEEE Transactions on Energy Conversion, vol. 25, Issue 3, pp. 821 835, 2010.

[13] M. Rossi, A. Toppano, and D. Brunelli, "Real-time optimization of the battery banks lifetime in hybrid residential electrical systems," in Proceedings of 2014 Design, Automation \& Test in Europe Conference \& Exhibition (DATE), Dresden, Germany, 24-28 March 2014, pp. 1-6.

[14] EXIDE Technologies, Industrial Energy, Handbook for Gel-VRLABatteries. In Part 2: Installation, Commissioning and Operation, Milton, Georgia, p. 22, 2013. 